\title{
The optimal legal retirement age in an OLG model with endogenous labour supply
}

\author{
by \\ Casper Worm Hansen \\ and \\ Lars Lønstrup
}

Discussion Papers on Business and Economics

No. 5/2009

FURTHER INFORMATION

Department of Business and Economics

Faculty of Social Sciences

University of Southern Denmark

Campusvej 55

DK-5230 Odense M

Denmark

Tel.: +4565503271

Fax: +4565503237

E-mail: 1ho@sam.sdu.dk 


\title{
The optimal legal retirement age in an OLG model with endogeneous labour supply
}

\author{
Casper Worm Hansen \\ University of Southern Denmark \\ Campusvej 55, 5230 Odense \\ cwh@sam.sdu.dk \\ and \\ Lars Lønstrup \\ University of Southern Denmark \\ Campusvej 55, 5230 Odense \\ loe@sam.sdu.dk
}

Version: July 2009

The long run welfare implications of the legal retirement age are studied in a perfect foresight overlapping-generations model where agents live for two periods. Agents' lifetime is divided between working life and retirement by a legal retirement age controlled by the government whereas agents, besides savings, control the intensive margin or "yearly" labour supply. The legal retirement age is utilized to dampen distortionary effects of payroll taxes and public pension annuities and promote capital accumulation. We show that a social optimal legal retirement age exists and how it depends on whether payroll taxes or benefit annuities ensures budget balance of the PAYG pension system.

Keywords: Optimal legal retirement age, pay-as-you-go-pension systems, overlappinggenerations model. 


\section{INTRODUCTION}

How should working hours be distributed throughout life? The legal retirement age is an important aspect of answering this question, since generous public pension systems discourage work beyond the legal retirement age. Therefore, the recently conducted pension system reforms around most of Western Europe may have important implications for how workers choose to allocate lifetime labour supply in the future. Even though the welfare implications of the reforms are a major concern, alterations of the legal retirement age have mainly been analysed in the context of budgetary concerns, whereas the direct impacts on the life cycle and thereby welfare have attracted less attention.

This paper aims at clarifying the impacts on individual welfare caused by a pay-as-you-go (PAYG) system, particularly focusing on the role played by the legal retirement age. With a long run perspective, this analysis has two aspects. On the one hand, the legal retirement age directly affects welfare since it influences how many years workers stay in the workforce. On the other hand, by determining the length of working life, the legal retirement age affects the need for private savings. This is important for welfare in the long run, since savings, causing capital accumulation, is essential for economic growth. This paper analyses these effects in detail. In particular, an optimal design of a PAYG pension should feature a legal retirement age that divides total life between working life and retirement in a way that takes into account both lifecycle and capital accumulation effects on long run welfare.

We show that there exists a socially optimal legal retirement age where the lifetime utility of the agents is maximised. This result is a consequence of two counteracting effects taking place as the legal retirement age is altered. For example, an increased legal retirement age, in itself, tends to increase lifetime labour supply and thereby income and savings. However, for higher values of the retirement age, a further increase makes workers choose fewer working hours per year, since they will ultimately work their whole lives. Therefore, for a sufficiently high legal retirement age, lifetime labour supply and savings may be lowered by increasing the legal retirement age. We will refer to these two counteracting effects as extensive and intensive effects, respectively.

We find that the socially optimal legal retirement age depends on the other parts of the PAYG pension system. If you change one of the three parts, to keep budget balance, one or two of the other parts must be changed as well. Hence, the socially optimal legal retirement age should be seen as one part of the optimal package. All three parts affect workers' decisions and are therefore distortionary by nature, since workers do not assign the real costs and benefits from leisure and savings in the presence of pay roll taxes and 
pension benefits. In this paper, the legal retirement age is introduced as a policy instrument with the potential to dampen such distortionary effects from the PAYG system. Under the restriction of budget balance, an increased retirement age makes it possible, all things being equal, to decrease yearly pay roll taxes and/or increase benefit annuities. Consequently, pension system reforms have important long run welfare effects, not only by directly affecting the length of working and retirement life, but also by changing the distortionary effects of the pension system. Therefore, we suggest that the proportionality between the observed increased longevity and the legal retirement age should depend on the other parts of the reform. For example, if the yearly pay roll tax rate is decreased along with an increased retirement age, we find less room for increasing the legal retirement age than if benefit annuities were increased.

Regarding distortionary effects on savings, it is well known that PAYG pension systems depress private saving and consequently capital accumulation (Samuelson, 1975). If you are provided with public pensions each year in your retired life you need less private savings for each year of your retired life. However, this is not the whole story of public pension systems and private savings. As first pointed out by Feldstein (1974), there may be a counteracting induced retirement effect. Public pension schemes also affect decisions via the legal retirement age. For example, by decreasing the age at which workers become eligible for public pensions, governments induce workers to retire earlier and thereby save for a longer retirement period, which tends to increase private savings. Even though workers have fewer years in which to save (the extensive effect), the increased propensity to save each year (the intensive effect) could be dominating. Hence, the introduction of a PAYG system where workers are eligible for (low) pension annuities sufficiently early would increase private savings. These counteracting intensive and extensive effects are captured in our model.

Another implication of adjusting the legal retirement age is that workforce participation is altered directly at the extensive margin, i.e. the number of years workers stay in the workforce. The famed empirical studies by Gruber and Wise $(1999,2004)$ show that the legal retirement age constitutes a highly effective instrument for governments. As Gruber and Wise (1998) put it, there is a strong correspondence between the age at which benefits are available and departure from the labour force. The conclusion is drawn from the success of public programmes intending to lower the workforce participation of older workers. The instrument was to provide public transfers at a lower age, intending to encourage earlier retirement of old and disabled workers. The ambition was to decrease unemployment among the remaining labour force. The reforms succeeded in lowering workforce participation of older (disabled) workers, but unemployment rates did not fall as much as hoped for. Our model reveals a simple relation that may be one of many possible explanations of this finding. 
Indeed, people have to work for a certain number of hours during life to obtain a certain consumption level during life. If social security systems encourage workers to retire earlier, then workers choose to work more intensively during their shorter working life, to maintain the same consumption level throughout life. Therefore, the intention of governments to decrease the workforce (at the extensive margin) by the legal retirement age may imply a non-negligible counteracting effect at the intensive margin. We believe this to be an equally important point regarding pension system reforms where the legal retirement age is increased.

The literature on retirement can be divided into two branches, the private retirement decision, and retirement in general equilibrium models. What drives the private retirement decision has been analysed for example by Sheshinksi (1978), Burbidge and Robb (1980) and Cremer et al. (2004). These papers perceive retirement as the point in time where agents prefer full time leisure, studied in a continuous time partial equilibrium framework with agents choosing a stream of consumption and leisure throughout life. The general finding is that agents retire when marginal utility from consuming net working income equals marginal utility from full time leisure. More closely related to this paper are contributions by $\mathrm{Hu}$ (1979) and Heijdra and Romp (2009) who study retirement in a general equilibrium OLG framework. Hu (1979) examines the effect of increased pension on lifetime utility and finds that increased pension level will increase the demand for leisure (earlier retirement) in the short run, while the long run effect is ambiguous since decreased capital accumulation affects factor prices. Optimal retirement in this analysis is then an outcome of a pension level that balances the cost of increased static inefficiency from higher pensions with benefits of decreased dynamic inefficiency. By assuming a small open economy, Heijdra and Romp (2009) do not consider capital accumulation and factor price effects of pension systems. Instead, they focus on the implications of the timing of eligibility of public pensions on the private retirement decision and show theoretical support for the findings of Gruber and Wise (1999, 2004), as workers endogenously retire at the earliest age at which they are eligible for public pensions. We deviate from the existing literature in the way agents are assumed to alter labour supply. In the existing literature, retirement is the outcome of a labour market participation decision: either full time work or no work at all. We take a different approach. In the model presented below, agents choose yearly working hours, whereas the retirement age by assumption coincides with the legal retirement age controlled by the government. We follow this alternative approach, because this paper focuses on long run effects of the legal retirement age. In such an analysis, we believe that the choice of yearly (intensive margin) labour supply matters a great deal more than the choice of retirement age (the extensive margin), with the empirical findings of Gruber and Wise in mind. 
The paper proceeds as follows. The demand side of the model is presented in the next section which offers the basic intuition behind the results. In section 3 we specify the supply side and calibrate the model, after which the simulation results on the socially optimal legal retirement age are presented. Section 4 concludes and provides some suggestions for future research. 


\section{THE MODEL}

Consider an overlapping-generations model in which agents live for two periods. Agents, all alike, are born at time $t$ and work in period $t$ (working life with length $\chi_{t}$ ) and retire in period $t+1$ (retirement with length $\phi_{t}-\chi_{t}$ ). The variable $\phi_{t}>0$ is exogenously determined limit-longevity or life expectancy, since we assume a survival rate of unity between the working life and retirement. The length of working life, $\chi_{t}$, we refer to as the legal retirement age (henceforth LRA) and we assume $0<\chi_{t}<\phi_{t}$. Technically, $\chi_{t}$ is an exogenous variable, which we imagine to be under government control.

The lifetime utility of an agent born at $t$ writes:

$$
U_{t}=\int_{0}^{\chi_{t}} u\left(c_{1, t}, l_{t}\right) d z+\int_{\chi_{t}}^{\phi_{t}} u\left(c_{2, t+1}, l^{e}\right) d z
$$

where the function $u$ is assumed to be strictly concave, satisfying $u_{c l}^{\prime \prime} \geq 0, u>0 .{ }^{1}$ The arguments $c_{1, t}$ and $l_{t}$ denote consumption and leisure in each "sub period" ${ }^{2}$ of working life. In retirement, consumption and leisure in each sub period are denoted by $c_{2, t+1}$ and $l^{e} .^{3}$ During working life, agents divide their time endowment between work $\left(n_{t}\right)$ and leisure $\left(l_{t}\right)$. Without loss of generality, we normalise the endowment of time in each sub period $\left(l^{e}\right)$ to unity

$$
l^{e} \equiv 1=n_{t}+l_{t}
$$

where $n_{t}$ is working time per sub period. Consequently, agents enjoy full time leisure in retirement by assumption.

From the strict concavity of $u$ and no discounting within working life $(\chi)$ and retirement $(\phi-\chi)$, optimising agents will choose to smooth consumption and leisure perfectly during working life as well as choosing perfect consumption smoothing in retirement. Therefore, (1) is rewritten as

$$
U_{t}=\chi_{t} u\left(c_{t}, l_{t}\right)+\left(\phi_{t}-\chi_{t}\right) u\left(c_{2, t+1}, l^{e}\right)
$$

Equation (3) reveals that lifetime utility is sub period utility in the working life and retirement, extended by their respective length. In the terminology of Philipson and Becker

\footnotetext{
${ }^{1}$ This model follows the literature on endogenous longevity on the assumption $u>0$. In this literature, the assumption ensures that agents prefer life to death. In our model, the assumption ensures a meaningful economic interpretation of the optimal LRA.

${ }^{2}$ We borrow this terminology from Auerbach and Hassett (2002).

${ }^{3}$ Except the state variable $k_{t}$ determined by savings, $s_{t}$, all variables are sub period variables. Since $k_{t}$ is the state variable taking the economy from period $t$ to period $t+1$, these two variables have to be measured as "gross variables", which means that $s_{t}$ is savings of the whole working period and $k_{t}$ is therefore the capital per worker employed during the whole working period $\left(\chi_{t}\right)$.
} 
(1998), sub period utility can be interpreted as the quality of life and the length of working life and retirement as the quantity of life. For a given LRA $\left(\chi_{t}\right)$, an increased lifetime $\left(\phi_{t}\right)$ would at first sight increase utility with the quality of life in retirement (measured by $\left.u\left(c_{2, t+1}\right)\right)$. In fact, this will only be the case if agents' income when retired is solely comprised of public pension annuities, i.e. no private savings. Since agents have private savings in this model, retirees would have to "stretch" their saving over a longer retirement if $\phi_{t}$ increased, i.e. the quality of life would decline for a given amount of savings. However, this is not the whole story, since agents, behaving optimally, will alter the quality of life in the working life and retirement upon changes in $\phi_{t}$ (or $\chi_{t}$ ).

In each sub period during working life, agents earn $w_{t}\left(1-l_{t}\right)$, pay taxes $\tau_{t} w_{t}\left(1-l_{t}\right)$ where $w_{t}$ is the real wage in each sub period and $\tau_{t}$ is the payroll tax rate. In addition, agents save an amount, $\frac{s_{t}}{\chi_{t}}$, in each sub period (where $\frac{1}{\chi_{t}}$ may be interpreted as the annuity cost of savings and $s_{t}$ is therefore "gross savings" from total working life):

$$
c_{1, t}=\left[1-\tau_{t}\right]\left[1-l_{t}\right] w_{t}-\frac{s_{t}}{\chi_{t}}
$$

During retirement, the annuity income from private savings, $\frac{R_{t+1} s_{t}}{\phi_{t}-\chi_{t}}$, and the public pension annuity $\Psi_{t+1} n_{t+1} w_{t+1}$ are consumed in each sub period

$$
c_{2, t+1}=\frac{R_{t+1} s_{t}}{\phi_{t}-\chi_{t}}+\Psi_{t+1}\left[1-l_{t+1}\right] w_{t+1}
$$

where $R_{t+1}$ denotes gross returns to savings, $\Psi_{t+1}$ denotes the rate out of sub period income of current workers (generation $t+1$ ), transferred to current retirees (generation $t$ ) which amounts to a public pension annuity of $\Psi_{t+1}\left[1-l_{t+1}\right] w_{t+1}$ during retirement. We will loosely refer to $\Psi_{t}$ as the "replacement rate".

The population evolves according to

$$
N_{t+1}=\left[1+b_{t}\right] N_{t}
$$

where $N_{t}$ is the size of generation $t$, and $b_{t} \in(-1,+\infty)$ denotes the growth rate of the population between generation $t+1$ and $t$. Generation $t+1$ is born into working life as generation $t$ gives birth to $N_{t}\left[1+b_{t}\right]$ at the end of working life. Let us here clarify the implications on demographics from the extensive length of the two life cycle periods. For example, if $\chi(1+m)=\phi$ there would be $m+2$ generations alive in period $t .{ }^{4}$ However, since the retirees, who "unusually" survive for more than one length of working life, are

\footnotetext{
${ }^{4}$ Where $m=0$ and $\chi_{t}=\phi_{t}=1$ is the classical case. If for example $m=2$, working life constitutes $\frac{1}{3}$ and retirement $\frac{2}{3}$ of total life. Then it takes three working periods before the retirees are dead, and therefore there will be four generations alive in each period $t$, since generation $t$ and $t-1$ live as usual, but generations $t-2$ and $t-3$ have not died yet biologically, but only "economically".
} 
passive in the sense that all economic decisions have been executed, they are unimportant for the dynamics of the economy. To avoid this problem, the existing literature dealing with extensive length of periods usually assumes a length of the working life of unity and a length of retirement between 0 and 1, implying a maximum lifespan of length 2 . In terms of the parameters of this model this corresponds to $\frac{1}{2} \leq \frac{\chi}{\phi}<1$, whereas our assumptions imply the less restrictive constraint $0<\frac{\chi}{\phi}<1$.

The government runs a PAYG pension scheme which is balanced in every period

$$
\tau_{t} w_{t}\left[1-l_{t}\right] \chi_{t} N_{t}=\Psi_{t} w_{t}\left[1-l_{t}\right]\left[\phi_{t-1}-\chi_{t-1}\right] N_{t-1}
$$

where it is assumed that $0<\tau_{t}<1$. Note that there is no such restriction on the replacement rate $\Psi_{t}$. For example, if the length of retirement is relatively low, the benefit annuities should be spread over very few years and retirees could receive more than $100 \%$ of yearly income of current workers. However, the restriction on $\tau_{t}$ implies that $0<\Psi_{t}<\frac{\chi_{t}\left[1+b_{t-1}\right]}{\phi_{t-1}-\chi_{t-1}}$, where $\frac{\chi_{t}\left[1+b_{t-1}\right]}{\phi_{t-1}-\chi_{t-1}}$ is the inverse dependency ratio. What is distinct about this system is that factor prices and thereby long run growth are irrelevant for balancing the pension system. This is a way of assuming that in the long run, the increased standard of living entirely transmits through the pension system. We assume that the PAYG system (7) is balanced by sole adjustments of either $\tau_{t}$ or $\Psi_{t}$ in response to changes in the LRA $\left(\chi_{t}\right)$. We refer to these stylised schemes as defined contribution (DC) where $\tau_{t}=\tau$ and a defined benefit (DB) system $\Psi_{t}=\Psi$, where sole adjustment of either the benefit rate $\left(\Psi_{t}\right)$ or the contribution rate $\left(\tau_{t}\right)$ ensures budget balance. Consequently, we rule out combinations of the two systems. ${ }^{5}$

We restrict the analysis to changes in the LRA, which entails a changed old age dependency ratio, $\frac{\phi_{t-1}-\chi_{t-1}}{\chi_{t}\left[1+b_{t-1}\right]}$. We should make clear that we do not analyse parametric reforms in response to ageing, i.e. how either $\tau_{t}, \Psi_{t}$ or $\chi_{t}$ should change in response to demographically related changes in the dependency ratio $(b$ and/or $\phi)$. Instead, we analyse how the optimal LRA depends on given demographic figures, which is a different exercise than to evaluate the (transition of) different parametric reforms responding to changed demographics.

\footnotetext{
${ }^{5}$ See for example Žamac (2007) for more on this topic.
} 
By inserting (4) and (5) into (3) we obtain the following unconstrained problem of an individual born at $t$ :

$$
\left.\max _{s_{t}, l_{t}} U=\chi_{t} u\left(\left[1-\tau_{t}\right]\left[1-l_{t}\right] w_{t}-\frac{s_{t}}{\chi_{t}}\right), l_{t}\right)+\left[\phi_{t}-\chi_{t}\right] u\left(\frac{R_{t+1} s_{t}}{\phi_{t}-\chi_{t}}+\Psi_{t+1} n_{t+1} w_{t+1}\right)
$$

The first order conditions for this problem $\operatorname{are}^{6}$

$$
\begin{gathered}
U_{s}(s, l, \chi, \phi)=-u_{c_{1}}^{\prime}\left(c_{1, t}, l_{t}\right)+R_{t+1} u_{c_{2}}^{\prime}\left(c_{2, t+1,} l^{e}\right)=0 \\
U_{l}(s, l, \chi, \phi)=-u_{c_{1}}^{\prime}\left(c_{1, t}, l_{t}\right)\left[1-\tau_{t}\right] w_{t}+u_{l}^{\prime}\left(c_{1, t,}, l_{t}\right)=0
\end{gathered}
$$

Equation (9) balances the marginal cost and benefit of life-cycle saving in terms of marginal utilities. Equation (10) equates the marginal loss in utility from giving up one marginal unit of sub period consumption for sub period leisure in the working life, to the marginal increase in sub period utility from increasing sub period leisure marginally. Although the conditions are standard, let us point out that these conditions work in sub period variables.

We use equations (4), (5), (9) and (10) to perform comparative statics to the variables leisure and savings, without regard for budget balance of the PAYG system. First, we show the effects of an exogenously increased LRA. (See Appendix A for proofs of the propositions.)

Proposition 1. An increased LRA has an ambiguous effect on savings. There exists a $\bar{\chi}$ such that $\frac{\partial s}{\partial \chi}>0$ if $\chi<\bar{\chi}$ and $\frac{\partial s}{\partial \chi}<0$, if $\chi>\bar{\chi}$.

The ambiguity is a result of counteracting intensive and extensive effects: as the LRA $(\chi)$ is increased, the length of retirement decreases, which lowers workers' propensity to save. On the other hand, increasing $\chi$ provides the opportunity to work and save for a longer time, which tends to increase savings. The net effect depends on $\chi$, which therefore determines the total effect. The idea of Proposition 1 is illustrated in figure 1.

\footnotetext{
${ }^{6}$ Here $U_{x}$ denotes the partial derivate of $U$ with respect to $x$.
} 


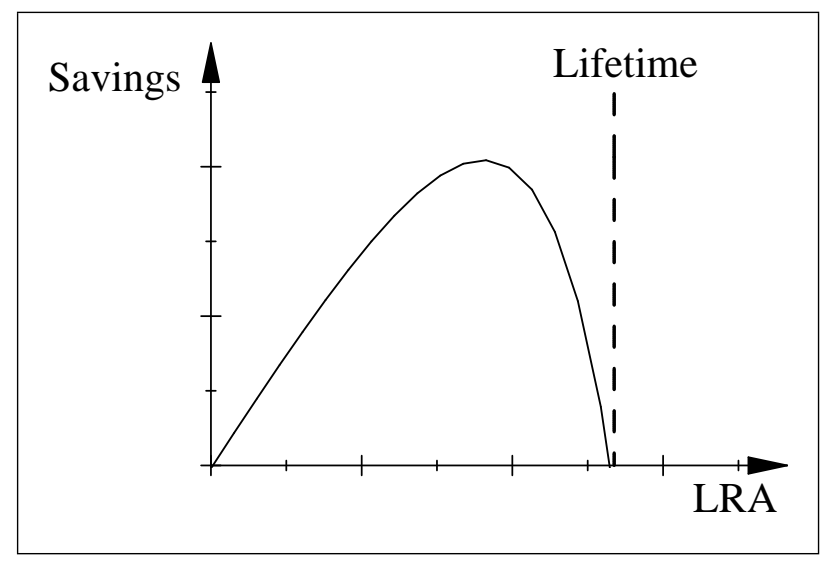

FIG. 1 Retirement age and savings

Proposition 2. An increased LRA has an ambiguous effect on sub period/yearly labour supply. There exists a $\hat{\chi}$ such that $\frac{\partial l}{\partial \chi}>0$ if $\chi<\hat{\chi}$ and $\frac{\partial l}{\partial \chi}<0$ if $\chi>\hat{\chi}$.

As stated in Proposition 1, workers lower savings when the LRA becomes sufficiently high, implying an increased demand for leisure, i.e. lower intensive labour supply. Together, Propositions 1 and 2 state that, given a sufficiently long working life ex ante, increasing the LRA would have a negative effect on both factors of production, namely capital and labour supply.

Proposition 3. An increase in longevity increases savings and sub period/yearly labour supply unambigiously.

In this simple partial analysis, the intuition behind the result is straightforward: for a constant LRA, an increase in the length of life forces the agent to save and work more to smooth consumption over the longer life span where the additional years add entirely to retirement.

Together, the propositions illustrate the implications of the intensive and extensive effects in the model, showing the direct and partial equilibrium impact on welfare when the (relative) length of the two periods of the life cycle is altered. We now include the production side to account for general equilibrium effects in the simulation results. 


\section{THE OPTIMAL LEGAL RETIREMENT AGE}

In this section, we study the optimal LRA in a general equilibrium framework. For this purpose we start out by presenting the production side of the economy. Next, we specify the functional forms for the utility function and define the equilibrium of the economy, after which the model is calibrated. Finally, we perform numerical simulations of the model to obtain values of the optimal LRA.

\section{The production side of the economy}

We describe the production of the single consumption good by a Cobb-Douglas production function, $Y_{t}=K_{t-1}^{\alpha}\left[N_{t} \chi_{t}\left(1-l_{t}\right)\right]^{1-\alpha}$, where we assume $0<\alpha<1$. The variable $Y_{t}$ denotes aggregate gross output (i.e. the flow of income from total working life), $K_{t-1}$ is the aggregate gross capital stock (i.e. the stock of capital accumulated during the entire working period) and $N_{t} \chi_{t}\left(1-l_{t}\right)$ denotes the aggregate gross labour supply. Defining $k_{t-1} \equiv \frac{K_{t-1}}{N_{t}}$ and $y_{t} \equiv \frac{Y_{t}}{N_{t}}$ as gross capital stock and output per worker, we rewrite the production function into per worker units $y_{t}=\left[k_{t-1}\right]^{\alpha}\left[\left(1-l_{t}\right) \chi_{t}\right]^{1-\alpha}$. In the competitive equilibrium, factors are paid the value of their marginal products:

$$
\begin{gathered}
R_{t}=\alpha\left[\frac{k_{t-1}}{\left(1-l_{t}\right) \chi_{t}}\right]^{\alpha-1} \\
w_{t}=[1-\alpha]\left[\frac{k_{t-1}}{\left[1-l_{t}\right] \chi_{t}}\right]^{\alpha}
\end{gathered}
$$

where $R_{t}$ is the gross real interest rate, assuming complete depreciation. The variable $w_{t}$ is the real wage. Market clearing conditions are given by

$$
\begin{gathered}
K_{t}=N_{t} s_{t} \\
Y_{t}=\chi_{t} N_{t} c_{1, t}+\left[\phi_{t-1}-\chi_{t-1}\right] N_{t-1} c_{2, t}+K_{t}
\end{gathered}
$$

\section{The functional form of the utility function}

We specify the sub period utility function as a nested constant elasticity of substitution function. With arguments from working lifewe we write $u$ as:

$$
u=a+\frac{1}{1-\gamma}\left[\left[c_{1, t}\right]^{1-\sigma}+\theta\left[l_{t}\right]^{1-\sigma}\right]^{\frac{1-\gamma}{1-\sigma}}, \gamma, \sigma>0 \wedge \gamma, \sigma \neq 1
$$

and with the arguments relevant for retirement we write $u$ as:

$$
u=a+\frac{1}{1-\gamma}\left[\left[c_{2, t+1}\right]^{1-\sigma}+\theta\left[l^{e}\right]^{1-\sigma}\right]^{\frac{1-\gamma}{1-\sigma}}, \gamma, \sigma>0 \wedge \gamma, \sigma \neq 1
$$

The parameter $\gamma>0$ denotes the constant elasticity of marginal utility. The inverse intratemporal elasticity of substitution between leisure and consumption is given by $\sigma>0$. 
The parameter $\theta>0$ measures the taste for leisure. In retirement, agents enjoy full time leisure by assumption, $l^{e} \equiv 1$.

The constant $a>0$ ensures that $u>0$ for all possible values of $\gamma$ and $\sigma .^{7}$ This assumption ensures that an increase in the LRA has a meaningful economic interpretation, which again ensures that the optimal LRA has a meaningful interpretation. In other words, the quality of life, measured as the utility levels in the two periods, is positive even if $\gamma>1$. Adding the same constant $a$ to $u$ in both working life and retirement has no influence on the optimal LRA. Moreover, this constant has no effect on (sub period) behaviour, since marginal utility is unaffected.

Before calibrating the model, we define the equilibrium for the economy.

The equilibrium of the economy

Definition 1 A competitive equilibrium of the economy is a sequence $\left\{c_{1, t}, c_{2, t+1}, l_{t}, k_{t-1},\right\}_{t=0}^{\infty}$ such that (i) $c_{1, t}, c_{2, t+1}, l_{t}$ maximises utility (8) under the periodic budget constraints (4) and (4) where factor prices, demographic variables and the legal retirement age are taken as given $\left\{R_{t}, w_{t}, \phi_{t}, \chi_{t}, b_{t}\right\}_{t=0}^{\infty}$, (ii) the government budget is balanced, production factors are paid their marginal product value and market clearing conditions are satisfied, i.e. (7), (11), (12), (13) and (14) hold, and (iii) $k_{0}>0$.

\section{Calibration}

The nest structure of the utility function allows leisure and consumption in working life to be substitutes or complements, with various intertemporal elasticities of substitution. In the baseline simulation we choose a parameter value of $\gamma=0.9$ reflecting that consumption bundles in the two periods of life are weakly substitutes. The elasticity of substitution between leisure and consumption is two, i.e., $\sigma=0.5$.

In the benchmark equilibrium, we calibrate the length of adult life to 60 years $\left(\phi_{s s}=60\right)$ and working life amounts to 40 years $\left(\chi_{s s}=40\right)$, meaning 20 years of retirement. We choose the replacement rate to be $\Psi=\frac{2}{5}$. For benchmark demographics, this implies a tax rate of $\tau=0.2$. The taste for leisure is calibrated to obtain a reasonable value $\left(l_{t}=0.69\right.$ $\Longleftrightarrow n_{t}=0.31$ ) of sub period labour supply in the benchmark equilibrium. The capital share of output is set as is standard in the literature at $\alpha=0.3$. The parameter values of the model are summarised in Table 1.

\footnotetext{
${ }^{7}$ See Hall and Jones (2007) on this issue.
} 
The optimal legal retirement age:

We define the (second best) $)^{8}$ optimal LRA $\chi^{*}$ to be the LRA that maximises the welfare of agents alive in the steady state of the competitive equilibrium. Let $\hat{U}(\chi)$ denote the indirect utility function, in steady state

$$
U(\chi)=\chi u\left(\tilde{c}_{1}^{*}(\chi), \tilde{l}^{*}(\chi)\right)+(\phi-\chi) u\left(\tilde{c}_{2}^{*}(\chi), l^{e}\right)
$$

and define the optimal LRA $\left(\chi^{*}\right)$ as

$$
\chi^{*}=\arg \max _{\chi} U(\chi)
$$

where an asterisk denotes that a variable is chosen optimally according to its first order conditions, and a tilde denotes a variable in units of labor, for example $\tilde{k}=\frac{k}{\chi(1-l)}$. Before presenting the numerical results, let us give the basic economic intuition of the mechanisms behind the optimal LRA. The first order condition for the optimal LRA is given by

$\frac{\partial \hat{U}(\chi)}{\partial \chi}=u\left(c_{1}\right)-u\left(c_{2}\right)+u^{\prime}\left(c_{1}\right)[1+b] k\left[f^{\prime \prime}(k) \frac{k}{\chi}\left[\varepsilon_{k \chi}-1\right]\left[\frac{1}{R}-\frac{1}{(1+b)}\right]+\frac{1}{\chi}+\frac{1}{(\phi-\chi)}\right]=0$

where for simplicity $\tau=0$ (no PAYG pension system). and $f(\tilde{k})$ is the production function in intensive form where $f^{\prime}>0$ and $f^{\prime \prime}<0$. The first two terms are effects at the extensive margin: retirement is replaced by time in working life. In addition the terms in brackets are effect at the intensive margin (the quality of life). The marginal utility of consumption in working life is affected positively, since the annuity cost of savings (expressed by the term $u^{\prime}\left(c_{1}^{*}, l^{*}\right) \frac{\tilde{k}}{\chi}(1+b)$ in $\left.(18)\right)$ decreases as the LRA increases. Marginal utility in retirement is also affected positively since the annuity return to savings increases as the LRA

\footnotetext{
${ }^{8}$ In the following we illustrate how $\chi^{*}$ is determined in an economy with no distortions $(\tau=0)$. However, in general, in addition to these considerations $\chi^{*}$ is affected by the size and the type of the PAYG system and therefore becomes second best optimal.
}

\begin{tabular}{cccc}
\hline $\begin{array}{c}\text { Parameters/ } \\
\text { Exogenous var. }\end{array}$ & $\begin{array}{c}\text { Benchmark } \\
\text { value }\end{array}$ & $\begin{array}{c}\text { Parameters/ } \\
\text { Exogenous var. }\end{array}$ & $\begin{array}{c}\text { Benchmark } \\
\text { value }\end{array}$ \\
\hline \hline$\gamma$ & 0.9 & $\Psi$ & 0.4 \\
$\sigma$ & 0.5 & $\chi$ & 40 \\
$\alpha$ & 0.3 & $\phi$ & 60 \\
$\theta$ & 1.5 & $b$ & 0 \\
$\tau$ & 0.2 & & \\
\hline
\end{tabular}

TABLE 1

Values of parameters and exogeneous variables 
increases, which in terms of marginal utility of working period consumption in (18) is given by $u^{\prime}\left(c_{1}^{*}, l^{*}\right) \frac{\tilde{k}}{\phi-\chi}(1+b)$. The remaining part of (18) concerns general equilibrium effects. The net production in steady state $(w)$ is affected in two ways as $\chi$ increases. At impact, the labor input increases tending to decrease $w$. However a longer working life may increase savings (see Proposition 1). The stronger effect determines the sign of $\left[\varepsilon_{k \chi}-1\right]$ and thereby the net effect on the capital labor ratio and $w$. Therefore, in a dynamic efficient economy $\varepsilon_{k \chi}>1$ ensures a positive value in the brackets of (18)

In addition to these effects, the simulations below takes into account the distortionary effects of the PAYG pension schemes. From (7) we have $\frac{\partial \tau_{t}}{\partial \chi}<0$ for a DB system and $\frac{\partial \Psi_{t}}{\partial \chi}>0$ for a DC system. Hence, in a DB (DC) system, increasing (decreasing) the LRA lowers the distortionary effects from the pension system. Together, all these effects determine the optimal LRA. To see the total effect we now run numerical simulations.

\section{Numerical simulation}

To perform the simulations, we follow the approach suggested by Boucekkine (1995) for saddle-point trajectories of non-linear deterministic models. This is done in the program Dynare (Juillard, 1996). This allows us easily to check whether the simulated steady states are locally stable. All steady state values in Tables 2 and 3 in Appendix B represent locally stable steady states.

The first row of Table 2 reports steady state values for the benchmark equilibrium, where $\chi$ is exogenously set to the value 40 , implying that $\chi$ is not optimally set in accordance with (17). The benchmark equilibrium comprises a PAYG pension replacement rate of $\Psi_{t}=0.4$ and a tax rate, $\tau_{t}=0.2$. In the benchmark case we find a capital output ratio of $\frac{k}{y}=0.17$.

In the subsequent rows we obtain the optimal LRA using (17). In Table 2 column 2 we obtain the optimal LRA for three cases: a DC system (scenario 1), a DB system (scenario 2) and a laissez faire economy without any pension system (referred to as scenario 3, or the first best solution). ${ }^{9}$ The two first scenarios are directly comparable with the benchmark equilibrium, whereas scenario 3 differs by definition from the benchmark by not featuring the pension system. Firstly, welfare is strictly larger when the LRA is adjusted according to (17), i.e. there is a steady state welfare gain by adjusting the LRA independent of how the pension system operates. Secondly, a DB system implies higher optimal LRA than a DC system. This occurs because a DB system allows for a lower tax rate as the LRA is increased. Therefore, a relatively long working life stimulates savings and labour supply because this

\footnotetext{
${ }^{9} \mathrm{By}$ definition, there is no pension system in the laissez faire economy and our story about retirement being driven by the legal retirement age is not valid in such a setting. Alternatively, one could think of $\chi$ as a mandatory retirement age where the government forces workers to leave the workforce at age $\chi$.
} 
lowers the tax rate and thereby the distortionary effects from the pension system. For a DC system the opposite holds. The tax rate is fixed and therefore the pension annuity rate increases as the length of retirement decreases or equivalently the LRA increases. Hence, relatively long retirement and a short working life stimulates savings the most, because this lowers benefit annuities and thereby the distortionary effects from the pension system since lower benefit annuities means less private saving is depressed. The fact that adjusting the LRA can reduce the distorting effects from the pension system explains why the optimal LRA in the first best solution is in the middle of scenarios 1 and 2 . We summarise these simulation results below:

Simulation result 1 There exists an optimal LRA. A pension system of the DB type implies that the optimal LRA is higher compared to the first best solution. A pension system of the DC type implies that the optimal LRA is lower compared to the first best solution. Of the second best solutions, steady state welfare is strictly higher in a DC system.

It is worth mentioning that intensive labour supply is higher (leisure lower) in a DC system compared to a DB system with the same benchmark, even though the tax rate maintains its benchmark value in the DC system, whereas the tax rate (and thereby the price on leisure) is lowered in the DB system as the LRA is increased to its optimal value. This is in line with Proposition 2. Additionally, when the tax rate and the LRA are linked through the budget balance of pension system, this can explain why we do not observe sensitivity of labour supply to pay roll taxes. Take the projected pressure on unfunded pension system caused by increasing old age dependency ratios as an example. With unchanged benefit annuities and no issuing of government debt, a constant LRA necessitates rising taxes and vice versa. If payroll taxes are gradually increased to cope with increasing longevity and a constant or even decreasing LRA, yearly labour supply may be left unaffected. Even though the lower price on leisure tends to decrease yearly labour supply a longer retirement period tends to increase yearly labour supply, since workers have the same number of years to work and save in but for a longer life span.

From (2b)-(2d) in Table 2 we observe how the optimal LRA is affected by different changes in demographic characteristics. Welfare in the second best solution is strictly higher in the DC system. Hence, the choice of DB versus a DC system with respect to long run welfare should not depend on long run demographic trends. This result is a consequence of the restricted choice of either keeping benefits or payroll taxes unchanged. If this is the choice politicians face then, in the long run, distortions from the pension system can be diminished 
the most by keeping payroll taxes unchanged. The optimal LRA in the DC system implies a relatively short working life and relatively long retirement life. The short working life entails lower and thereby less distorting payroll tax. As indicated, workers care less about taxes as the working years shrink. Furthermore, longer retirement promotes savings for two reasons in a DC system: i) a longer retirement period induces, all things being equal, more private savings and ii) the DC system implies lower benefit annuities implying less displacement of private savings. The counteracting effect is of course that less income is earned, all things being equal, as the length of working life shrinks.

As expected, we find that the optimal LRA rises with longevity (see (2d)). Moreover, observe that the relative optimal LRA is constant for a given population growth rate and pension system $\left(\frac{\chi_{D C}^{*}}{\phi} \approx 0.5\right.$ and $\left.\frac{\chi_{D B}^{*}}{\phi} \approx 0.68\right)$. In $(2 \mathrm{~b})-(2 \mathrm{c})$ we also see that a lower population growth rate increases the optimal LRA. We summarise these simulation results below.

Simulation result 2 There exists an optimal length of working life relative to total lifespan, for a given population growth rate and pension system. This implies that the LRA should be raised equiproportionally with increased life expectancy if the LRA is set optimally ex ante. Of the second best solutions, steady state welfare is strictly higher with a DC type pension system independently of demographics.

Table 3 offers a sensitivity analysis of these abovementioned results. Let us briefly comment on them. Increasing the taste for leisure $(\theta)$ implies a lower optimal LRA. Since leisure, per definition, is full time after agents have retired, the quality of life is increased the most in retirement if $\theta$ is increased. Intuitively, the optimal LRA is decreasing in the preference for leisure. In Table 3 (b) we observe that the optimal LRA is decreasing in $\gamma$. However, the simulation results regarding the optimal LRA are not sensitive to variation in this parameter. Finally, in Table 3 (c), we find that the optimal LRA is increasing in $\sigma$. We find the optimal LRA to be sensitive to variation in this parameter and the welfare result in Simulation result 1 can be reversed. However, a necessary condition for this to happen is $\sigma>1$, which implies a negative relation between the real wage and labour supply (per sub period). If this is the case, the steady state welfare of the second best solutions is higher in a DB type pension system, and therefore reverses the welfare result. We sum up as follows:

Simulation result 3 Increasing the taste for leisure lowers the optimal legal retirement age. The optimal legal retirement age is not very sensitive to variation in the intertemporal elasticity of substitution. However, the optimal legal retirement age is sensitive to variation in the elasticity of substitution between leisure and consumption and the welfare result in the second best solution can be reversed. 
To summarise, the optimal LRA depends on demographics and social security. A DC (DB) system always implies an earlier (later) optimal LRA compared to the first best solution, since this will diminish the distorting effects from the pension system the most. For most reasonable parameter values, steady state welfare in the second best solution is higher with a DC-PAYG system. We find that there exists an optimal relative LRA (relative to the length of life, i.e. $\frac{\chi_{t}}{\phi_{t}}$ ). Therefore, the LRA should, all things being equal, be increased equiproportionally with increased longevity, given that the LRA was set optimally ex ante. 


\section{CONCLUDING REMARKS}

We have studied the long run macroeconomic effects of the legal retirement age (LRA) in an overlapping generations model where the government is able to control when people retire. The main findings are the following. Alterations of the LRA for the purpose of increasing the workforce have counteracting effects on the yearly labour supply. This result is explained as follows: i) if workers work for more years they need to work less per year to earn the same lifetime income and ii) the payroll tax financing public pension annuities become increasingly distorting as the length of working life increases. This illustrates that the LRA has important long run welfare implications and we show that an optimal relative LRA exists (relative to the total length of life). The optimal LRA is characterised by diminishing the distortions on labour supply and savings from unfunded public pension systems of the PAYG type. Regarding increasing longevity, in the long run, the LRA should be indexed to total length of life if the LRA is set optimally ex ante. If the payroll taxes are held constant at the present level, it may be a good strategy not to increase (or at least modestly increase ) the LRA in response to increasing longevity. The most important welfare improving effect from such a policy is that increased longevity will imply a lower public pension annuity rate in the future (when the payroll tax rate is held constant), which promotes capital accumulation. In short, we have shown that besides coping with the future budget balance of unfunded pension systems, the LRA can be utilised to increase long run welfare compared to a given benchmark level of payroll taxes and benefit annuities.

Our results rely heavily on the assumption that the government perfectly controls when workers leave the workforce. A natural extension would be a privately decided retirement age. In such an analysis, it will be appropriate to allow for variations in the design of pension systems, for example by a closer link between individual contributions and benefit, i.e. elements of what is known as a Bismarckian pension scheme. Another decisive element for retirement decisions is of course morbidity, the risk of death and health in general, which also are increasingly important regarding public program expenditures on the elderly. In other words, to study the private retirement decision and its long run implications, actuarial design and eligibility conditions of the pension system together with heterogeneous health conditions of workers and retirees would be key elements. 


\section{References}

Auerbach A.J., and K.A. Hassett, (2002), Optimal long-run fiscal policy: Constraints preferences and the resolution of uncertainty, Journal of Economic Dynamics and Control, vol. 31, pp. 1451-1472.

Becker, G.S., T.J. Philipson, and R.R. Soares, (2005), The Quantity and Quality of Life and the Evolution of World Inequality, The American Economic Review, vol. 95, No.1, pp. 277-329.

Boucekkine, R., (1995), An alternative methodology for solving non-linear forward looking models, Journal of Economic Dynamics and Control, vol. 19, No. 4, pp. 711-734.

Burbidge, J.B., and A.L. Robb, (1980), Pensions and retirement behaviour, Canadian Journal of Economics, vol. 13, pp. 421-437.

Börsch-Supan, A., and R. Schnabel, (1998), Social Security and Declining labour-Force Participation in Germany, The American Economic Review, vol. 88, No. 2, pp. 173-178.

Chakraborty, S., and M. Das, (2005), Mortality, Human Capital and Persistent Inequality, Journal of Economic Growth, vol. 10, pp. 159-192.

Cremer, H, J. Lozachmeur, and P. Pestieau, (2004), Social security, retirement age and optimal income taxation, Journal of Public Economics, vol. 88, pp. 2259- 2281.

Cremer, H., and P. Pestieau, (2003), The double dividend of postponing retirement, International Tax and Public Finance, vol. 10, No. 4, pp. 419-434.

De la Croix, D., and P. Michel, (2002), A Theory of Economic Growth: Dynamics and Policy in Overlapping Generations, Cambridge University Press, Cambridge.

Diamond, A., (1965), National debt in a neoclassical growth model, American Economic Review, vol 55 (December), pp. 1126-1150.

Feldstein, M., (1974), Social security induced retirement and aggregate capital accumulation, The Journal of Political Economy, vol. 82, No. 5, pp. 905-926.

Gruber, J., and D.A. Wise, (1998), Social Security and Retirement: An International Comparison, The American Economic Review, vol. 88, No. 2, pp. 158-163.

Gruber, J., and D.A. Wise, (1999), Introduction and summary. In: Gruber, J., Wise, D.A. (Eds.), Social Security and Retirement around the World. University of Chicago Press, Chicago, pp. 1-35. 
Gruber, J., and D.A. Wise, (2004), Introduction and summary. In: Gruber, J., Wise, D.A. (Eds.), Social Security Programs and Retirement around the World: Microestimation. University of Chicago Press, Chicago, pp. 1-35.

Hall, R and C. Jones, (2007), The value of life and the rise in health spending, The Quarterly Journal of Economics, February 2007.

Heijdra, B.J., and W.E. Romp, (2009), Retirement, pensions, and ageing, Journal of Public Economics, vol. 93, Issues 5-6, pp. 647-830.

Hu, S.C., (1979), Social Security, the Supply of labour, and Capital Accumulation, The American Economic Review, vol. 69, No. 3, pp. 274-283.

Jensen, S., and O.H. Jørgensen, (2007), Uncertain Demographics, Longevity Adjustment of the Retirement Age, and Intergenerational Risk Sharing, Discussion paper on Business and Economics, University of Southern Denmark.

Juillard, M., (1996), A program for the resolution and simulation of dynamic models with forward variables through the use of a relaxation algorithm. Working Paper, CEPREMAP.

Lacomba, J. A., and F. Lagos, (2006), Population aging and legal retirement age, Journal of Population Economics, vol. 19, pp. 507-519.

OECD, (2007), Pension at a glance, OECD, Paris.

Philipson, T., and G. Becker (1998), Old-age longevity and mortality-contingent claims, Journal of Political Economy, vol. 106, pp. 551-573.

Samuelson P., (1975), Optimum social security in a life-cycle growth model, International Economic Review, vol. 16, No. 3, pp. 531-537.

Sheshinksi, E., (1978), A model of social security and retirement decisions, Journal of Public Economics vol. 10, pp. 337-360.

Žamac, J., (2007), Pension design when fertility fluctuates: The role of education and capital mobility, Journal of Public Economics, vol. 91, pp. 619-639.

Zhang, J., J. Zhang, and M.C. Leung, (2006), Health investment, saving, and public policy, Canadian Journal of Economics, vol 39, No. 1, pp. 68-83. 


\section{Appendix A}

Proof of Proposition 1 and 2

From maximisation we have (we leave out the time notation for simplicity)

$$
\begin{gathered}
U_{s}(s, l, \chi, \phi)=-u_{c_{1}}^{\prime}\left(c_{1}, l\right)+R u_{c_{2}}^{\prime}\left(c_{2}\right)=0 \\
U_{l}(s, l, \chi, \phi)=-u_{c_{1}}^{\prime}\left(c_{1}, l\right)(1-\tau) w+u_{l}^{\prime}\left(c_{1}, l\right)=0
\end{gathered}
$$

Where $c_{1}=(1-\tau)(1-l) w-\frac{s}{\chi}$ and $c_{2}=\frac{R s}{\phi-\chi}+\Psi w(1-l)$

The Hessian $H$ of $U$ then reads

$$
H=\left(\begin{array}{cc}
U_{s s} & U_{s l} \\
U_{l s} & U_{l l}
\end{array}\right)
$$

To allow the problem to have a unique solution, we assume the Hessian of $U$ to be a negative definite. That is, $\left|U_{s s}\right|<0$ and $|H|>0$. (or $U_{l l} U_{s s}-U_{l s}^{2}>0$ ) where

$$
\begin{gathered}
U_{s s}=\frac{u_{c_{1} c_{1}}^{\prime \prime}}{\chi}+R^{2} u_{c_{2} c_{2}}^{\prime \prime}<0 \\
U_{l s}=U_{s l}=u_{c_{1} c_{1}}^{\prime \prime} w(1-\tau)-u_{c_{1} l}^{\prime \prime}<0 \\
U_{l l}=u_{c_{1} c_{1}}^{\prime \prime}((1-\tau) w)^{2}-u_{c_{1} l}^{\prime \prime}(1-\tau) w+u_{l l}^{\prime \prime}<0 \\
U_{s \chi}=-\frac{u_{c_{1} c_{1}}^{\prime \prime} s+u_{c_{2} c_{2}}^{\prime \prime} \frac{R^{2} s}{\chi^{2}}(\phi-\chi)^{2}}{\chi^{2}}+u_{l c_{1}}^{\prime \prime} \frac{s}{\chi^{2}}>0
\end{gathered}
$$

Differentiating (19) and (20) with respect to $\chi$ yields

$$
\begin{gathered}
U_{s \chi}+U_{s s} \frac{\partial s}{\partial \chi}+U_{s l} \frac{\partial l}{\partial \chi}=0 \\
U_{l \chi}+U_{l s} \frac{\partial s}{\partial \chi}+U_{l l} \frac{\partial l}{\partial \chi}=0
\end{gathered}
$$

Solving the system in (21) using Cramer's rule gives

$$
\begin{aligned}
& \frac{\partial s}{\partial \chi}=\frac{\left|\begin{array}{cc}
-U_{s \chi} & U_{s l} \\
-U_{l \chi} & U_{l l}
\end{array}\right|}{|H|} \\
& \frac{\partial l}{\partial \chi}=\frac{\left|\begin{array}{ll}
U_{s s} & -U_{s \chi} \\
U_{l s} & -U_{l \chi}
\end{array}\right|}{|H|}
\end{aligned}
$$

Notice that $|H|>0$, so the sign of $\frac{\partial s}{\partial \chi}$ is determined by the sign of the determinant in the numerator. Then we have (for simplicity we assume $\tau=0$ )

$$
\operatorname{sign} \frac{\partial s}{\partial \chi}=-s\left(\begin{array}{c}
{\left[\phi^{2}+\chi^{2}-2 \phi \chi\right]\left(u_{c_{1} l}^{\prime \prime}\right)^{2}-\left[\phi^{2}+\chi^{2}-2 \phi \chi\right] w u_{c_{1} l}^{\prime \prime} u_{c_{1} c_{1}}^{\prime \prime}+R u_{c_{2} c_{2}}^{\prime \prime} \chi^{2} u_{l l}^{\prime \prime}+} \\
R w^{2} u_{c_{2} c_{2}}^{\prime \prime} \chi^{2} u_{c_{1} c_{1}}^{\prime \prime}-R w u_{c_{2} c_{2}}^{\prime \prime} \chi^{2} u_{c_{1} l}^{\prime \prime}-\left[\phi^{2}+\chi^{2}-2 \phi \chi\right] u_{c_{1} c_{1}}^{\prime \prime} u_{l l}^{\prime \prime}
\end{array}\right) \gtrless 0
$$


The sign of (24) is ambiguous. However, observe that as $\chi$ approaches $\phi$ (i.e. later retirement) the sign of $\frac{\partial s}{\partial \chi}$ tends to be negative. Because as $\chi$ approaches $\phi$, the term $\phi^{2}+\chi^{2}-2 \phi \chi$ goes to zero and $-s\left(R u_{c_{2} c_{2}}^{\prime \prime} \chi^{2} u_{l l}^{\prime \prime}+R w^{2} u_{c_{2} c_{2}}^{\prime \prime} \chi^{2} u_{c_{1} c_{1}}^{\prime \prime}-R w u_{c_{2} c_{2}}^{\prime \prime} \chi^{2} u_{c_{1} l}^{\prime \prime}\right)<0$, due to the assumptions $u_{c_{1} c_{1}}^{\prime \prime}<0, u_{l l}^{\prime \prime}<0, u_{c_{2} c_{2}}^{\prime \prime}$ and $u_{c_{1} l}^{\prime \prime}>0$.

Solving the determinant of the numerator of (23) gives $\operatorname{sign} \frac{\partial l}{\partial \chi}=-\frac{s}{\chi^{3}} \frac{u_{c_{1} l}^{\prime \prime}-w u_{c_{1} c_{1}}^{\prime \prime}}{(\phi-\chi)^{2}}\left(\left[\phi^{2} \chi-2 \phi \chi^{2}+2 \chi^{3}\right] u_{c_{2} c_{2}}^{\prime \prime} R^{2}+\left[\frac{\chi}{\phi}-\phi+\frac{\phi}{\chi}+2 \chi-2-\frac{\chi^{2}}{\phi}\right] \chi \phi u_{c_{1} c_{1}}^{\prime \prime}\right) \lessgtr$

The sign of (25) is ambiguous. However if we rewrite (25) as

$$
\overbrace{\left[\phi-2 \chi+\frac{2 \chi^{2}}{\phi}\right]}^{\Lambda_{1}} R^{2}>\overbrace{\left[-\frac{\chi}{\phi}+\phi-\frac{\phi}{\chi}-2 \chi+2+\frac{\chi^{2}}{\phi}\right]}^{\Lambda_{2}} \frac{u_{c_{1} c_{1}}^{\prime \prime}}{u_{c_{2} c_{2}}^{\prime \prime}}
$$

If this expression is true, then $\frac{\partial l}{\partial \chi}>0$. We now observe the following; $\Lambda_{1}$ is always positive (given our assumption $\phi>\chi$ ) and as $\chi$ approaches $\phi$ the term $\Lambda_{2}$ goes to zero. So in this case (26) holds with inequality. Moreover for $\chi \leq 1$ the term $\Lambda_{2}$ becomes nonpositive. In this case (26) also holds with inequality. Hence, $\chi \leq 1$. is a sufficient condition to ensure $\frac{\partial l}{\partial \chi}>0$. 


\section{Appendix A}

Proof of Proposition 3:

How a rise in longevity affects savings is given by

$$
\frac{\partial s}{\partial \phi}=\frac{\left|\begin{array}{cc}
-U_{s \phi} & U_{s l} \\
-U_{l \phi} & U_{l l}
\end{array}\right|}{|H|}
$$

The determinant in the numerator is then given by $U_{l s} U_{l \phi}-U_{l l} U_{s \phi}$. Further observe that $-U_{l \phi}=0, U_{s \phi}=-\left(\frac{R}{\phi-\chi}\right)^{2} u_{c_{2} c_{2}}^{\prime \prime}<0$ and $U_{l l}<0$ (from Appendix A).Thus, $U_{l s} U_{l \phi}-$ $U_{l l} U_{s \phi}>0$ implying that $\frac{\partial s}{\partial \phi}>0$

$$
\frac{\partial l}{\partial \phi}=\frac{\left|\begin{array}{cc}
U_{s s} & -U_{s \phi} \\
U_{l s} & -U_{l \phi}
\end{array}\right|}{|H|}
$$

The determinant in the numerator is then given by $U_{l s} U_{s \phi}-U_{s^{2}} U_{l \phi}$, which gives

$$
-u_{c_{2} c_{2}}^{\prime \prime} u_{c_{1} c_{1}}^{\prime \prime} w+u_{c_{1} l}^{\prime \prime} u_{c_{2} c_{2}}^{\prime \prime}<0
$$

So increasing longevity lowers the demand for leisure and thereby increases labour supply. 


\subsection{Appendix B}

Deriving the first order condition for the optimal legal retirement age.

With $\tau=0$ (i.e. no PAYG system) the indirect utility function, $\hat{U}$, in the steady state is given by

$$
\hat{U}(\chi)=\chi u\left(\left[1-l^{*}\right] w-\frac{s^{*}}{\chi}, l^{*}\right)+[\phi-\chi] u\left(\frac{R s^{*}}{\phi-\chi}, l^{e}\right)
$$

where an asterisk $l^{*}\left(s^{*}\right)$ indicates that leisure (savings) is chosen optimally according to its first order conditions. For notational ease, let $f(\tilde{k})$ be the production function in intensive form, where $\tilde{k} \equiv \frac{k}{\left[1-l_{t}\right] \chi}$ and $f(\tilde{k})$ obeys $f^{\prime}(\tilde{k})>0$ and $f^{\prime \prime}(\tilde{k})<0$. The real wage and real rate of return are then

$$
\begin{aligned}
& R=f^{\prime}(\tilde{k}) \\
& w=f(\tilde{k})-k f^{\prime}(\tilde{k})
\end{aligned}
$$

The capital market equation reads

$$
[1+b] \tilde{k}=\tilde{s}^{*}
$$

Substituting these condition in (27) gives the indirect utility function per worker in steady state as a function of $\tilde{k}$

$\left.\hat{U}(\chi)=\chi u\left([1-l]\left(f(\tilde{k})-\tilde{k} f^{\prime}(\tilde{k})\right)-(1+b) \tilde{k}[1-l]\right), l\right)+[\phi-\chi] u\left(\frac{f^{\prime}(\tilde{k}) \tilde{k}[1-l] \chi(1+b)}{\phi-\chi}\right)$

where $k$ is an implicit function of $\chi$.

The first order condition reads

$\frac{\partial \hat{U}(\chi)}{\partial \chi}=u\left(c_{1}\right)-u\left(c_{2}\right)+u^{\prime}\left(c_{1}\right)[1+b] k\left[f^{\prime \prime}(k) \frac{k}{\chi}\left[\varepsilon_{k \chi}-1\right]\left[\frac{1}{R}-\frac{1}{(1+b)}\right]+\frac{1}{\chi}+\frac{1}{(\phi-\chi)}\right]=0$

where $\varepsilon_{k \chi} \equiv \frac{\partial k(\chi)}{\partial \chi} \frac{\chi}{k(\chi)}$. Concavity of $\hat{U}$ wrt. $\chi$ ensures a maximum.

\section{Appendix B}




\begin{tabular}{|c|c|c|c|c|c|c|c|}
\hline & & $\begin{array}{l}\text { Retire- } \\
\text { ment } \\
\text { age }\end{array}$ & $\begin{array}{l}\mathrm{RR} / \\
\operatorname{tax} \\
\text { rate }\end{array}$ & $\begin{array}{l}\text { Steady } \\
\text { state } \\
\text { leisure }\end{array}$ & $\begin{array}{l}\text { Steady } \\
\text { state } \\
\text { capital }\end{array}$ & $\begin{array}{l}\text { Steady } \\
\text { state } \\
\text { output }\end{array}$ & $\begin{array}{c}\text { Steady } \\
\text { state } \\
\text { welfare }\end{array}$ \\
\hline & & $\chi$ & $\psi / \tau$ & $l$ & $k$ & $y$ & $U$ \\
\hline (1) & Benchmark & 40 & $0.4 / 0.2$ & 0.69 & 0.95 & 5.77 & 608.14 \\
\hline (2a) & $\begin{array}{l}\text { The opt. } \\
\text { retirement } \\
\text { age: } \\
\text { system }\end{array}$ & & & & & & \\
\hline$(2 \mathrm{a} .1)$ & DC-PAYG & 30 & $0.2 / 0.2$ & 0.62 & 1.31564 & 5.91 & 608.99 \\
\hline$(2 \mathrm{a} .2)$ & DB-PAYG & 41 & $0.4 / 0.18$ & 0.69 & 0.96 & 5.88 & 608.16 \\
\hline$(2 \mathrm{a} .3)$ & No PAYG & 37 & $0 / 0$ & 0.58 & 2.12 & 8.60 & 610.50 \\
\hline$(2 b)$ & $\begin{array}{c}\text { Population } \\
\text { growth rate: } \\
\quad b=-0.2\end{array}$ & & & & & & \\
\hline$(2 \mathrm{~b} .1)$ & DC-PAYG & 32 & $0.18 / 0.2$ & 0.63 & 1.62 & 6.50 & 608.77 \\
\hline \multirow[t]{2}{*}{$(2 \mathrm{~b} .2)$} & DB-PAYG & 46 & $0.4 / 0.17$ & 0.70 & 1.09 & 6.42 & 607.51 \\
\hline & No PAYG & 40 & 0 & 0.59 & 2.62 & 9.51 & 610.88 \\
\hline$(2 c)$ & $\begin{array}{c}\text { Population } \\
\text { growth rate : } \\
\quad b=0.2\end{array}$ & & & & & & \\
\hline$(2 \mathrm{c} .1)$ & DC-PAYG & 29 & $0.22 / 0.2$ & 0.62 & 1.11 & 5.52 & 609.24 \\
\hline \multirow[t]{2}{*}{$(2 \mathrm{c} .2)$} & DB-PAYG & 38 & $0.4 / 0.18$ & 0.68 & 0.85 & 5.53 & 608.73 \\
\hline & NoPAYG & 35 & $0 / 0$ & 0.57 & 1.78 & 7.96 & 610.34 \\
\hline$(2 d)$ & $\begin{array}{l}\text { Longevity: } \\
\qquad \begin{array}{l}\phi=70\end{array}\end{array}$ & & & & & & \\
\hline$(2 \mathrm{~d} .1)$ & DC-PAYG & 35 & $0.2 / 0.2$ & 0.62 & 1.53 & 6.90 & 710.49 \\
\hline$(2 \mathrm{~d} .2)$ & DB-PAYG & 48 & $0.4 / 0.18$ & 0.69 & 1.12 & 6.88 & 709.52 \\
\hline$(2 \mathrm{~d} .3)$ & No PAYG & 43 & $0 / 0$ & 0.57 & 2.49 & 10.03 & 712.20 \\
\hline
\end{tabular}

TABLE 2

Optimal retirement age and steady state values. RR: replacement rate 


\begin{tabular}{|c|c|c|c|c|c|c|c|}
\hline & & $\begin{array}{c}\text { Retire- } \\
\text { ment } \\
\text { age }\end{array}$ & $\begin{array}{l}\mathrm{RR} / \\
\text { tax } \\
\text { rate }\end{array}$ & $\begin{array}{c}\text { Steady } \\
\text { state } \\
\text { leisure }\end{array}$ & $\begin{array}{l}\text { Steady } \\
\text { state } \\
\text { capital }\end{array}$ & $\begin{array}{l}\text { Steady } \\
\text { state } \\
\text { output }\end{array}$ & $\begin{array}{c}\text { Steady } \\
\text { state } \\
\text { welfare }\end{array}$ \\
\hline & & $\chi$ & $\psi / \tau$ & $l$ & $k$ & $y$ & $U$ \\
\hline & $\begin{array}{c}\text { Variation in } \\
\text { parameter } \\
\text { values }\end{array}$ & & & & & & \\
\hline (a) & $\begin{array}{l}\text { Leisure taste } \\
\quad \theta=0.5\end{array}$ & & & & & & \\
\hline (a.1) & DC PAYG & 33 & $0.24 / 0.2$ & 0.38 & 1.91 & 10.09 & 566.82 \\
\hline (a.2) & DB PAYG & 42 & $0.4 / 0.17$ & 0.43 & 1.50 & 10.48 & 565.91 \\
\hline (a.3) & NO PAYG & 39 & $0 / 0$ & 0.32 & 3.01 & 13.81 & 570.33 \\
\hline (b) & $\begin{array}{l}1 / C E S \\
\gamma=0.5\end{array}$ & & & & & & \\
\hline (b.1) & DC-PAYG & 32 & $0.23 / 0.2$ & 0.60 & 1.64 & 6.86 & 130.35 \\
\hline (b.2) & DB-PAYG & 42 & $0.4 / 0.17$ & 0.66 & 1.34 & 7.05 & 129.81 \\
\hline (b.3) & $\begin{array}{c}\text { NO PAYG } \\
\begin{array}{c}\gamma=1.5 \\
(a=15)\end{array}\end{array}$ & 39 & & 0.56 & 2.58 & 9.72 & 131.65 \\
\hline (b.4) & DC-PAYG & 28 & $0.18 / 0.2$ & 0.66 & 1.02 & 5.01 & 787.56 \\
\hline (b.5) & DB-PAYG & 40 & $0.4 / 0.2$ & 0.72 & 0.65 & 4.76 & 786.37 \\
\hline (b.6) & No PAYG & 35 & $0 / 0$ & 0.60 & 1.70 & 7.49 & 789.22 \\
\hline (c) & $\begin{array}{l}1 / \mathrm{CES} \\
\sigma=1.5\end{array}$ & & & & & & \\
\hline (c.1) & DC-PAYG & 39 & $0.37 / 0.2$ & 0.30 & 2.20 & 12.90 & 460.02 \\
\hline (c.2) & DB-PAYG & 43.5 & $0.4 / 0.09$ & 0.31 & 1.95 & 13.14 & 460.14 \\
\hline (c.3) & No PAYG & 43 & $0 / 0$ & 0.31 & 3.57 & 15.70 & 463.91 \\
\hline
\end{tabular}

TABLE 3

Optimal retirement age and steady state values. RR: replacement rate 